\title{
Hypoxia after stroke: a review of experimental and clinical evidence
}

\author{
Phillip Ferdinand ${ }^{1 *}$ and Christine Roffe ${ }^{2}$
}

\begin{abstract}
Background: Hypoxia is a common occurrence following stroke and associated with poor clinical and functional outcomes. Normal oxygen physiology is a finely controlled mechanism from the oxygenation of haemoglobin in the pulmonary capillaries to its dissociation and delivery in the tissues. In no organ is this process more important than the brain, which has a number of vascular adaptions to be able to cope with a certain threshold of hypoxia, beyond which further disruption of oxygen delivery potentially leads to devastating consequences. Hypoxia following stroke is common and is often attributed to pneumonia, aspiration and respiratory muscle dysfunction, with sleep apnoea syndromes, pulmonary embolism and cardiac failure being less common but important treatable causes. As well as treating the underlying cause, oxygen therapy is a vital element to correcting hypoxia, but excessive use can itself cause molecular and clinical harm. As cerebral vascular occlusion completely obliterates oxygen delivery to its target tissue, the use of supplemental oxygen, even when not hypoxic, would seem a reasonable solution to try and correct this deficit, but to date randomised clinical trials have not shown benefit.

Conclusion: Whilst evidence for the use of supplemental oxygen therapy is currently lacking, it is vital to rapidly identify and treat all causes of hypoxia in the acute stroke patient, as a failure to will lead to poorer clinical outcomes. The full results of a large randomised trial looking at the use of supplemental oxygen therapy are currently pending.
\end{abstract}

Keywords: Cerebral hypoxia, Acute stroke, Oxygen therapy, Oxygen physiology, Cerebral blood flow

\section{Background}

Hypoxia is common after stroke, and associated with poor outcomes. In this article, we have reviewed the physiology of oxygen transport, the cerebrovascular response to hypoxia and pathophysiology, incidence and aetiology behind hypoxia in stroke and its subsequent clinical consequences. We have then reviewed all randomised clinical trials looking at the use of supplemental oxygen therapy in acute stroke and made conclusions regarding current evidence and recommendations for clinical practice.

\section{Oxygen physiology}

The normal adult range of arterial oxygen pressure $(\mathrm{PaO} 2)$ is $11.0-14.4 \mathrm{kPa}$ and the normal range for arterial oxygen saturation $(\mathrm{SaO} 2)$ is $95-98 \%$ [1]. The term hypoxia refers

\footnotetext{
*Correspondence: phillip.ferdinand@nhs.net

1 The Royal Wolverhampton NHS Trust, Wolverhampton WV10 0QP, UK Full list of author information is available at the end of the article
}

to oxygen levels below normal. It includes both tissue (e.g. brain, myocardium) hypoxia and hypoxia in the blood (hypoxaemia). Tissue hypoxia is defined by the concentration of oxygen in blood and also tissue perfusion, whilst hypoxaemia is defined by the concentration of oxygen in inspired air and its transfer into the blood [2].

Following inhalation oxygen is taken up in the lung capillaries via diffusion down an oxygen concentration gradient across the alveoli $[3,4]$. Oxygen binds to the haemoglobin molecule, which can carry four oxygen molecules; each binding and changing the shape of the haemoglobin molecule and increasing its affinity for oxygen [5]. A small amount of oxygen is also dissolved in plasma. This proportion increases in hyperoxia, when all haemoglobin is saturated [6]. Oxygen dissociates from the haemoglobin molecule in the tissues owing to the relatively hypercapnic and acidic environment (the Bohr effect) [3].

Oxygen is a vital substrate that supports virtually all metabolic processes. $90 \%$ of oxygen intake is engaged in 
the cytochrome $\mathrm{C}$ oxidase system in the mitochondria [7] generating adenosine triphosphate (ATP), which acts as the main energy substrate within cells. A continuous supply of oxygen is required to secure a continuous supply of ATP maintaining sufficient energy for cerebral neuronal and cellular activity. This facilitates an efficient energy producing process making 38 molecules of ATP during aerobic respiration, equivalent to 1270 joules (J) energy, in comparison to two molecules of ATP (67 J of energy) during anaerobic respiration $[7,8]$.

\section{The anoxic brain}

$20 \%$ of all human oxygen consumption is utilised by the brain [9]. The brain has no oxygen or glucose (the other important substrate in the ATP producing equation) stores. Thus complete disruption of cerebral blood flow very rapidly results in an anoxic, hypoglycaemic state, which via a variety of mechanisms ultimately leads to cell death. Excitatory neurotransmitters, such as glutamate, bind to a variety of receptors and allow for an influx of calcium ions that help formulate the chemical signal for depolarisation $[10,11]$. Normally the re-uptake of glutamate is an active energy-driven process. In the absence of ATP this process fails, resulting in an extracellular accumulation of glutamate, which continually stimulates receptors leading to a persistent influx of calcium ions [12]. Furthermore, the $\mathrm{Na}+/ \mathrm{Ca} 2+\mathrm{ATP}$ driven pump normally used to eliminate calcium fails, also due to a lack of ATP [13]. The resultant high intracellular calcium triggers multiple cascades that ultimately lead to mitochondrial dysfunction and cell death. Furthermore, instead of producing ATP, glial cells have been shown to release ATP extracellularly [11]. Aside from rendering this unusable by mitochondria, ATP also stimulates the P2X7 receptor, which again leads to significant calcium influx and ultimately cell death [13]. The other major mechanism of cellular demise is via the formation of free radicals facilitated by the reduction of iron from its ferric $(\mathrm{Fe} 3+)$ to its ferrous $(\mathrm{Fe} 2+)$ form and the initiation of inflammatory cascades [12].

\section{Cerebral blood flow in hypoxia}

In normoxic states, cerebral blood flow is very tightly controlled by the partial pressure of carbon dioxide $\left(\mathrm{PaCO}_{2}\right)$. Any hypocapnic state will result in vasoconstriction and reduction in regional cerebral blood flow and a hypercapnic state leads to the reverse with vasodilatation and an increase in cerebral blood flow. Cerebral blood flow is somewhat less responsive to changes in $\mathrm{PaO}_{2}$, which has the opposite effect to carbon dioxide; a hypoxic state causing cerebral vasodilatation with the aim of improving oxygen delivery and a hyperoxic state causing vasoconstriction $[14,15]$.
In a hypoxic state, whilst the vasodilatory response improves flow, the detection of hypoxia by peripheral chemoreceptors will in turn lead to an increase in respiratory drive, increasing arterial oxygen content. However, the consequence of this is also an increase in the clearance of carbon dioxide, which would theoretically cause vasoconstriction and reduced cerebral blood flow [9]. It appears there is a threshold to which the hypoxic response predominates (and the carbon dioxide one attenuated) at $\mathrm{a}^{\mathrm{PaO}_{2}}$ of around $50-60 \mathrm{mmHg}[9,14]$. Whilst the carbon dioxide mediated vascular response is mediated via a direct change in vessel wall $\mathrm{pH}$ [15], the oxygen response appears to be mediated by the deoxygenated erythrocyte via a number of mechanisms; which include release of ATP and the subsequent actions of endothelial nitric oxide synthase on the vessel wall, reduction of nitrite to nitric oxide and the activity of S-nitrosohaemoglobin [9].

The cerebral vascular response to hypoxia is not uniform. A study found that in an induced isocapnic hypoxic state increases in cerebral blood flow were most prominent in basal ganglia nuclei, the putamen, thalamus, nucleus accumbens and pallidum [16]. Studies of blood flow in individual vessels have found that flow in the internal carotid artery is maintained during hypoxia and that vertebral artery flow is increased [17]. This had led to the hypothesis that blood flow is increased in this region to preserve vital brainstem structures, or that possibly the posterior circulation vasculature is less susceptible to the effects of carbon dioxide for similar reasons.

\section{Neurological effects of hypoxia}

The neurological consequences of hypoxia are dependent upon the speed of onset, the severity of hypoxia, and the level of tissue perfusion. Rapid decreases in $\mathrm{PaO}_{2}$, as in a cardiorespiratory arrest, can lead to permanent neurological damage within minutes. However, lower, less abrupt changes, can be tolerated if the decrease in oxygen occurs in a gradual manner, such as ascending at altitude, where individuals can acclimatise and develop tolerance to lower oxygen partial pressures or, (to a lesser degree), in chronic smokers. Initial clinical features include altered judgement, difficulty in completing complex tasks, and impairment in short term memory [18, 19], but in the longer term deficits can be more widespread and span physical and neuropsychological domains. Seizures occur in up to a third of individuals within a day of exposure to hypoxia, and are commonly partial complex or myoclonic in nature. Intractable forms of either of these types of seizure are associated with a poor prognosis [20]. Cognitive impairment domains include amnesia, visuospatial deficits, frontal lobe symptoms, impairment of executive function, and impairments in language [21]. 
These are covered in more detailed reviews on the subject $[22,23]$. Involvement of the basal ganglia, a region particularly susceptible to hypoxic injury, can result in delayed Parkinsonism in older subjects, dystonia mainly in younger people, choreo-athetosis, and tremors [20]. Varying degrees of unilateral or bilateral motor impairment may be observed depending on both the anatomical level and extent of corticospinal tract involvement. In very rare cases, the syndrome of delayed post-hypoxic leukoencephalopathy may occur weeks after a seemingly rapid recovery from the original insult. This condition is characterised by rapid deterioration in cognition, emergence of extra-pyramidal signs, and loss of executive function as a results of severe demyelination [24]. The severity of leukoencephalopathy can be assessed by magnetic resonance imaging (MRI) [20]. Electroencephalography, somatosensory evoked potentials and MRI can provide valuable information about the severity of hypoxic injury, but also aid in prognostication together with overall clinical state [25].

\section{Hypoxia in the context of a stroke}

There is no specific definition as to what constitutes hypoxia in an acute stroke, and it is therefore reasonable to assume that normal values for the general population apply.

Sulter and colleagues [26] monitored 49 consecutive patients who presented with an acute stroke within $12 \mathrm{~h}$ duration using pulse oximetry for $48 \mathrm{~h}$. Patients were considered hypoxic and treated with supplemental oxygen if saturations were below $96 \%$ for more than 5 min. This occurred in $63 \%$ [31] of patients, with 28 of those returning to 'normal' oxygen saturations following administration of up to $5 \mathrm{~L} / \mathrm{min}$ of oxygen. The remaining three required much higher concentrations. Factors associated with hypoxia in this group were stroke severity, presence of dysphagia, and older age. Roffe et al. [27] recruited 118 patients (100 of whom had adequate measurements by pulse oximetry) and found that the mean daytime awake $\mathrm{SO}_{2}$ was $94.5 \pm 1.7 \%$ in stroke patients and $95.8 \pm 1.7 \%$ in healthy controls. Nocturnal saturations were reduced to $93.5 \pm 1.9 \%$ in the stroke group and $94.3 \pm 1.9 \%$ in controls. In the stroke group the average $4 \%$ oxygen desaturation index (ODI) (number of times per hour the saturation dipped more than $4 \%$ from baseline) was higher than in controls. At night almost a quarter of the stroke group had desaturations below $90 \%$. The same group also looked further at the differences between day and night oxygen saturations [28]. In stroke patients who were not hypoxic (defined as $\mathrm{SaO}_{2}$ less than 90\%) during the day, baseline daytime saturations were measured between 9am and 9pm and nocturnal saturation between $10 \mathrm{pm}$ and $6 \mathrm{am}$. In total 40 patients were recruited and in addition to $\mathrm{SaO}_{2}$, respiratory rate and sleep/awakeness was measured twice in each time period. The mean respiratory rate day vs. night was 20 and 18 breaths per minute respectively. The mean daytime $\mathrm{SaO}_{2}$ was $95.5 \%$ (87-98.6\%) and $94.3 \%(80-98 \%)$ at night. There was a strong correlation between respiratory rate, $\mathrm{SaO}_{2}$ and the 4\% ODI, making it clear that borderline daytime hypoxia could predict nocturnal hypoxic episodes. Comparisons in a later study were then made with matched controls overnight [29]. In this study the mean nocturnal oxygen saturations were found to be $0.5 \%$ less than controls, with the lowest measured desaturation in this group of $79.4 \%$, still almost $6 \%$ lower than the control group. The largest difference was in the percentage of patients with more than 10 desaturations per hour (42\% stroke vs. $15 \%$ controls). Hand et al. [30] performed a study looking at the feasibility of MRI as an imaging modality in hyperacute stroke assessment. One of the eligible 138 patients for the study could not be scanned owing to pulmonary oedema severe enough to cause considerable hypoxia. For a variety of reasons it was only possible to consistently measure oxygen saturations in 61 out of 85 patients. In those in whom saturations could reliably be measured, 11 out of 61 developed hypoxia (lowest $74 \%$ ) and of those who received oxygen during the scan only two could be monitored successfully. This highlights not only the prevalence of hypoxia in acute stroke, but the logistical difficulties acute hypoxia may pose for assessment. Another study examined the effect of five different, but randomly ordered body positions, each for $10 \mathrm{~min}$ on the impact on oxygen saturation [31]. Interestingly, lying on the left hand side reduced oxygen saturations, but only in those who hand a right hemiparesis. Those who were able to sit in a chair were able to achieve much higher mean $\mathrm{SaO}_{2}$, albeit suffering from more minor strokes. It was felt that a severe stroke, with a right hemiparesis and underlying chest disease were the greatest predictors of desaturation, but only when lying on the left side. A subsequent systematic review [32] comprising of three randomised controlled trials (173 patients) and one case controlled trial (10 patients) found that body position only played a role in oxygen saturations if patients had underlying respiratory co-morbidities.

The risk of aspiration is well documented in acute stroke (see below), but independent of this the question as to whether feeding (oral or nasogastric) contributes to hypoxia has also been examined. Dutta et al. [33] reported that nasogastric feeding caused no decrease in $\mathrm{SaO}_{2}$. A later study [34] found a small but statistically non-significant trend towards hypoxia when tube fed, in particular in patients that were fed overnight. Rowat and colleagues looked at the impact of oral feeding on oxygen saturations, using hospitalised elderly patients and 
young healthy controls as comparators [35]. The baseline $\mathrm{SaO}_{2}$ was lower in the stroke cohort than the other two, with a very small decrease in $\mathrm{SaO}_{2}$ with oral feeding in the stroke $(0.1 \%)$ and the elderly groups. Nearly a quarter of stroke patients dropped $\mathrm{SaO}_{2}$ to less than $90 \%(16 \%$ elderly, $0 \%$ young), but this did not occur in close relation to the time of swallowing, and thus no immediate risk could be attributed to oral feeding.

There is relatively little research on the correlation between hypoxia and clinical outcome. Hypoxia has been shown to be an independent clinical risk factor for post stroke dementia [36]. Rowat et al. [37] found that hypoxic patients were more likely to have respiratory disease and this led to an increased mortality. A smaller study looked at the prevalence of hypoxia in patients undergoing rehabilitation and found no significant difference in mean $\mathrm{SaO}_{2}$ at baseline, in nocturnal $\mathrm{SaO}_{2}$, the lowest nocturnal $\mathrm{SaO}_{2}$ or in the $4 \%$ ODI [38]. In conclusion, no association between $\mathrm{SaO}_{2}$ and functional outcome was found. Hypoxia has, however, been shown to correlate with the degree of white mater disease on MRI. White matter hyperintensity volumes were greatest in obstructive sleep apnoea (OSA) patients compared with non-OSA patients and more explicitly in hypoxic compared to non-hypoxic patients [39].

\section{Causes of hypoxia in acute stroke}

Pneumonia is a frequent complication of acute stroke. A recent consensus defined the term stroke-associated pneumonia (SAP) as a representation of a spectrum of lower respiratory tract disorders occurring within 7 days after the onset of stroke [40]. The criteria were based on a modified version of the centre for disease control (CDC) criteria, with a probable SAP fulfilling all CDC criteria but not meeting typical chest radiography changes and definite SAP fulfilling all CDC criteria including typical chest X-ray changes. In addition the consensus group concluded that there was a limited role for C-reactive protein, white blood cell count and other inflammatory biomarkers in the diagnosis [40]. A meta-analysis of 64 studies showed that the definition of stroke-associated pneumonias varied widely [41].

The incidence of pneumonia post stroke has been reported to range between 1 and 44\% [42, 43] and has been shown to increase mortality (threefold) and overall hospital care costs [42]. Two recent studies have looked at the utility of prophylactic antibiotics to reduce pneumonia. The STROKE-INF study [44] randomised patients with acute stroke and dysphagia to 7 days of prophylactic antibiotics (to be commenced within $48 \mathrm{~h}$ of stroke onset) or standard care and found no reduction in the incidence of pneumonia (OR 1.21, 95\% CI 0.71-2.08, $\mathrm{p}=0.489$ ). The PASS study [45] investigated the effects of prophylactic ceftriaxone and found that this did not affect functional outcome at 3 months. While there was a significant reduction in infections overall, there was no effect on the incidence of pneumonia (OR 0.67 95\% CI $0.39-1.15, \mathrm{p}=0.18$ ). Therefore, current evidence does not support the use of antibiotic prophylaxis to prevent pneumonia. There are several validated risk scores which can help the clinician to identify patients at high risk of stroke-associated pneumonia [46-48]. Given the considerable morbidity and mortality, and the lack of benefit from prophylactic treatment, highlighting patients at high risk to allow early identification and treatment of established infection is important in the care of stroke patients.

Aspiration is a frequent cause of pneumonia post stroke, especially in patients with dysphagia. Dysphagia is seen in up to $50 \%$ of ischaemic strokes [49], although the reported incidence can vary between studies. Individuals suffering from dysphagia were three times more likely to develop pneumonia and this number increased to eleven times if they were shown to aspirate [50]. Often aspiration occurs silently (reported in up to $40 \%$ ), that is, with few or no clinical signs. The presence of either dysphagia or a subsequent pneumonia is predictors of a worse clinical outcome [51]. An often neglected aspect of stroke treatment is oral care. Poor oral hygiene leads to proliferation of bacteria and debris in the oral cavity [52], which are liable to be aspirated causing respiratory tract infection [53]. This is particularly important in nasogastric tube fed patients in whom oral care can easily be missed.

Sleep apnoea is a common cause of intermittent nocturnal hypoxia after stroke, affecting up to $60 \%$ of patients [54]. This condition has also been shown to be a risk factor for future stroke and stroke mortality, if not appropriately treated. A few small studies have shown that nocturnal continuous positive airway pressure ventilation is feasible $[55,56]$, and can improve wellbeing in some stroke patients with sleep apnoea during the acute and rehabilitation phase, but compliance with the intervention is poor, especially in patients with delirium or cognitive impairment [57]. Obstructive sleep apnoea can cause or accentuate many traditional vascular risk factors, in particular hypertension [58] and atrial fibrillation [59], and has been shown to be an independent risk factor for stroke [54, 57,60]. A review of the cohort of the Wisconsin Sleep Study found a significant association between sleep disordered breathing and stroke prevalence, the more severe the indices of sleep apnoea, the greater the risk [61].

Respiratory muscle function is also a potential cause of hypoxia either directly by associated muscle paralysis or as a result of a secondary infection. Several studies have shown (some in comparison to matched controls) 
a significant reduction in forced vital capacity, forced expiratory volume in one second, peak expiratory flow rate and maximal inspiratory and expiratory pressures [62-64], suggesting impairment in function of accessory respiratory muscles as well as the diaphragm. This may pave the way for treatment strategies aiming to improve respiratory muscle function [65].

Less common stroke complications resulting in hypoxia include pulmonary embolism, which despite its low incidence in most reported series (around 1\%), is associated with increased in hospital mortality (31.5 vs $12.7 \%$ in a review of over 11,000 patients in the Registry of the Canadian Stroke Network), length of stay and severity of disability [66]. The risk of pulmonary embolism can persist for up to 4 weeks post stroke [67]. A review of a relatively small cohort of cryptogenic stroke patients found a significant incidence of silent pulmonary embolism (37\%), but did not comment as to whether or not this led to a resultant hypoxic state [68]. Improvements in mechanical, pharmacological and therapy based regimes are the likely reason pulmonary embolism is now a relative rarity. Cardiac failure and very rarely neurogenic pulmonary oedema $[69,70]$ are among the other causes.

\section{Oxygen therapy for acute stroke}

Oxygen treatment can be used to maintain normal oxygen saturation or to increase the oxygen saturation above normal in patients with acute stroke. The rationale for the latter is that blood with higher oxygen content may improve oxygen action in ischaemic brain areas [2]. When considering oxygen treatment it is important to weigh up potential adverse effects against benefits.

\section{Potential adverse effects of oxygen treatment after stroke} Oxygen treatment is not without side effects. Attachment to a wall delivery system as an inpatient restricts mobility in the acute phase and may represent an infection risk. In critical ill states or when bordering on the anaerobic threshold for exercise capacity, the body has several intrinsic systems to increase oxygen tension and deliver oxygen at the required rate in order to produce ATP and meet energy demands. One of the by-products of ATP formation is the formation of oxygen free-radical species, which, if not dealt with, can lead to cell apoptosis and developmental of tissue damage. In normal states the body has several intrinsic enzymes to neutralise free radicals by pairing them with so called donor electrons to form substances like oxygen or hydrogen peroxide which can then be efficiently removed. When high concentrations of oxygen are given this leads not only to increased oxygen delivery from red blood cells but also increased delivery via plasma. This then by-passes and overrides usual mechanism of clearance and is one the reasons tissue damage develops in inappropriately high concentrations of oxygen [71-73]. The cascade outlined above is only partially reversed during reperfusion, even though oxygen delivery has improved. Most of the clinical problems surrounding oxygen toxicity initially affect the lungs. High concentrations of oxygen may displace all nitrogen present in the alveoli and owing to the significant alveolar plasma gradient, the oxygen rapidly diffuses and dissolves into the plasma, effectively reducing the alveolar volume and leading to subsequent collapse. Hyperoxia may also impair mucilliary clearance and alter surfactant properties which may cause an 'adhesive collapse' [73, 74]. Neurological consequences outside of those described in the context of stroke include cerebral vasoconstriction, a by-product of excessive free radical formation, confusion, and seizures [73]. Oxygen toxicity more often occurs during use of high concentrations of oxygen or in hyperbaric conditions. In the clinical setting a stroke patient is exposed to, these are highly unlikely scenarios to occur.

\section{Recommendations from national and international stroke guidelines}

A review of the most recent societal guidelines shows uniformity in the approach to oxygen therapy in acute ischaemic stroke. The Royal College of Physicians guidelines [75] advise use of supplemental oxygen only if oxygen saturation drops below $95 \%$ and is not contraindicated, and recommends no supplemental oxygen for saturations of $95 \%$ or above. The European Stroke Organisation [76] advises supplemental oxygen use for oxygen saturations of less than $95 \%$. The American Heart Association/American Stroke Association Guidelines [77] advise that in the pre-hospital setting, oxygen supplementation to maintain oxygen saturations above $94 \%$ is reasonable and recommended for suspected stroke patients and that on presentation to hospital saturations should be continually monitored to watch out for hypoxia. This guidance is based on the American Heart Association post cardiac arrest guidelines [78] and thus the same advice applies to stroke patients. Again the guidelines do not support the use of hyperbaric oxygen therapy.

\section{Randomised controlled trials of supplemental oxygen in acute stroke}

A plausible solution to aid the correction of cerebral hypoxia in stroke would be to provide supplemental oxygen therapy in the acute phase, potentially helping to correct or prevent many of the catastrophic cerebral changes that may occur. To date 6 randomised controlled trials have tested this hypothesis. A quasi-randomised study of routine oxygen supplementation within the 
first $24 \mathrm{~h}$ of acute stroke by Ronning and Guldvog [79] showed that routine oxygen treatment $(3 \mathrm{~L} / \mathrm{min}$ for $24 \mathrm{~h}$ ) in unselected stroke patients did not reduce morbidity or mortality. Subgroup analyses suggested worse outcomes in patients with mild strokes treated with oxygen and a trend towards better outcomes in severe strokes (Scandinavian stroke scale score $<40$ ), but the study was not large enough to identify with certainty those who are likely to derive benefit. Oxygen saturation before or during treatment was not reported and it is therefore impossible to determine whether or not oxygen was ineffective because it failed to improve oxygen saturation or because of a genuine lack of effect on the ischaemic brain. A small study $(\mathrm{n}=16)$ delivered oxygen at a rate of $45 \mathrm{~L} / \mathrm{min}$ for $8 \mathrm{~h}$, commencing with $12 \mathrm{~h}$ of stroke onset. Perfusion-diffusion mismatch on MRI showed that cerebral blood volume and blood flow within ischaemic regions improved in the hyperoxia. Neurological deficit improved at $4 \mathrm{~h}$ (during treatment), $24 \mathrm{~h}$ and at 1 week. By $24 \mathrm{~h}$ MRI of the brain showed reperfusion and (asymptomatic) petechial haemorrhages in $50 \%$ of hyperoxia treated patients and $17 \%$ of controls $(\mathrm{p}=0.06)$. No long-term clinical benefit was seen at 3 months [80]. This study was too small to draw reliable conclusions, leading to a larger (unpublished) study by the same group (http://www. clinicaltrials.gov/ct2/show/NCT00414726?term=singha $1 \&$ rank $=1$ ) which initially planned to enrol 240 patients, randomising to either room air or high flow oxygen (30$45 \mathrm{~L} / \mathrm{min}$ for $8 \mathrm{~h}$ ) within $9 \mathrm{~h}$ of acute stroke onset. After enrolment of 85 patients, the study was terminated early due to an imbalance of deaths favouring the control arm, though it is noted that the excess in mortality in the treatment group was not considered related to the treatment by an external blinded assessor. An Indian study [81] enrolled 40 patients within $12 \mathrm{~h}$ of an acute anterior circulation ischaemic stroke and a National Institute Stroke Scale of more than 4 to receive either $10 \mathrm{~L} / \mathrm{min}$ for $12 \mathrm{~h}$ via face mask in the treatment group versus room air or $2 \mathrm{~L} / \mathrm{min}$ to keep oxygen saturation above $95 \%$. There was no significant difference in NIHSS, modified Rankin or Barthel index scores between the two groups. There was also no statistically significant difference between DWI lesion volumes in either group, though there was a trend towards smaller lesions in the treatment group.

In the Stroke Oxygen Pilot study [82], oxygen was given for $72 \mathrm{~h}$ and the dose was dependent on baseline oxygen saturation $(2 \mathrm{~L} / \mathrm{min}$ if the saturation was $>93 \%, 3 \mathrm{~L} / \mathrm{min}$ if the saturation was $93 \%$ or less). Initial results showed that the treatment regime increased oxygen saturation by about $2 \%$ in the treatment arm and this was associated with a small, but significant improvement in neurological recovery at one week. At 6 months [83] there was no statistically significant difference between the two groups, although there remained a small trend towards overall benefit with supplemental oxygen. This data led to the Stroke Oxygen Study $\left(\mathrm{SO}_{2} \mathrm{~S}\right)$ [84], in which 8003 patients within $24 \mathrm{~h}$ of hospital admission with acute stroke were randomized 1:1:1 to receive either continuous supplemental oxygen, supplemental oxygen only at night $(9 \mathrm{pm}-7 \mathrm{am})$ oxygen, or no supplemental oxygen treatment for $72 \mathrm{~h}$. This study has completed recruitment and is expected to report in 2016.

\section{Conclusion}

Oxygen is a vital substrate to the continual function and survival of cerebral tissue. Rapid reduction in partial pressures can very rapidly lead to catastrophic and permanent cerebral injury and physical disability. Whilst evidence does not currently support the additional supplementation of oxygen to stroke patients, it remains important to prevent hypoxia in stroke patients by identifying and treating reversible causes rapidly. Results of the Stroke Oxygen Study will provide new evidence of whether prophylactic oxygen treatment can prevent neurological deterioration and improve recovery.

\section{Authors' contributions}

PF and CR both equally participated in the search of the literature and writing of the manuscript. Both authors read and approved the final manuscript.

\section{Author details}

${ }^{1}$ The Royal Wolverhampton NHS Trust, Wolverhampton WV10 0QP, UK. ${ }^{2}$ Stroke Research in Stoke, Institute for Applied Clinical Studies, Keele University, Keele, Staffordshire, UK.

\section{Acknowledgements}

None

\section{Competing interests}

The authors declare that they have no competing interests.

Consent for publication

No individual patient information used.

Received: 24 August 2016 Accepted: 26 November 2016

Published online: 07 December 2016

\section{References}

1. Williams AJ. Assessing and interpreting arterial blood gases and acid-base balance. Br Med J. 1998:317(7167):1213-6.

2. Roffe C, Corfield D. Hypoxaemia and stroke. Rev Clin Gerontol. 2008;18(04):299-311.

3. Dunn JO, Mythen MG, Grocott MP. Physiology of oxygen transport. BJA Educ. 2016;16(10):341-8.

4. Treacher D, Leach R. ABC of oxygen: oxygen transport-1. Basic principles. Br Med J. 1998;317(7168):1302.

5. Thomas C, Lumb AB. Physiology of haemoglobin. Contin Educ Anaesth Crit Care Pain. 2012;12(5):251-6.

6. Law R, Bukwirwa H. The physiology of oxygen delivery. Update Anaesth. 1999;10(1-2):39.

7. Habler OP, Messmer KF. The physiology of oxygen transport. Transfus Sci. 1997;18(3):425-35.

8. Ward J. Oxygen delivery and demand. Surgery (Oxford). 2006;24(10):354-60. 
9. Hoiland RL, Bain AR, Rieger MG, Bailey DM, Ainslie PN. Hypoxemia, oxygen content, and the regulation of cerebral blood flow. Am J Physiol Regul Integr Comp Physiol. 2016;310(5):R398-413.

10. Guo MF, Yu JZ, Ma CG. Mechanisms related to neuron injury and death in cerebral hypoxic ischaemia. Folia Neuropathol. 2011;49(2):78-87.

11. Nathaniel TI, Williams-Hernandez A, Hunter AL, Liddy C, Peffley DM, Umesiri FE, et al. Tissue hypoxia during ischemic stroke: adaptive clues from hypoxia-tolerant animal models. Brain Res Bull. 2015;114:1-12.

12. Vijayakumar T, Sangwan A, Sharma B, Majid A, Rajanikant G. Cerebral ischemic preconditioning: the road so far.... Mol Neurobiol. 2016:53(4):2579-93.

13. Mifsud G, Zammit C, Muscat R, Di Giovanni G, Valentino M. Oligodendrocyte pathophysiology and treatment strategies in cerebral ischemia. CNS Neurosci Ther. 2014;20(7):603-12.

14. Ogoh S, Nakahara H, Ueda S, Okazaki K, Shibasaki M, Subudhi AW, et al. Effects of acute hypoxia on cerebrovascular responses to carbon dioxide. Exp Physiol. 2014;99(6):849-58.

15. Mardimae A, Balaban DY, Machina MA, Battisti-Charbonney A, Han JS, Katznelson $\mathrm{R}$, et al. The interaction of carbon dioxide and hypoxia in the control of cerebral blood flow. Pflugers Arch. 2012;464(4):345-51.

16. Binks AP, Cunningham VJ, Adams L, Banzett RB. Gray matter blood flow change is unevenly distributed during moderate isocapnic hypoxia in humans. J Appl Physiol. 2008;104(1):212-7.

17. Ogoh S, Sato K, Nakahara H, Okazaki K, Subudhi AW, Miyamoto T. Effect of acute hypoxia on blood flow in vertebral and internal carotid arteries. Exp Physiol. 2013;98(3):692-8.

18. Blass JP, Gibson GE. Consequences of mild, graded hypoxia. Adv Neurol. 1979;26:229-50.

19. Gibson GE, Pulsinelli W, Blass JP, Duffy TE. Brain dysfunction in mild to moderate hypoxia. Am J Med. 1981;70(6):1247-54.

20. Howard RS, Holmes PA, Koutroumanidis MA. Hypoxic-ischaemic brain injury. Pract Neurol. 2011;11(1):4-18.

21. Lu-Emerson C, Khot S. Neurological sequelae of hypoxic-ischemic brain injury. NeuroRehabilitation. 2010;26(1):35-45.

22. Lim C, Alexander MP, LaFleche G, Schnyer DM, Verfaellie M. The neurological and cognitive sequelae of cardiac arrest. Neurology. 2004;63(10):1774-8.

23. Caine D, Watson JD. Neuropsychological and neuropathological sequelae of cerebral anoxia: a critical review. J Int Neuropsychol Soc 2000;6(1):86-99.

24. Shprecher D, Mehta L. The syndrome of delayed post-hypoxic leukoencephalopathy. NeuroRehabilitation. 2010;26(1):65-72.

25. Howard RS, Holmes PA, Siddiqui A, Treacher D, Tsiropoulos I, Koutroumanidis M. Hypoxic-ischaemic brain injury: imaging and neurophysiology abnormalities related to outcome. QJM. 2012;105(6):551-61.

26. Sulter G, Elting JW, Stewart R, den Arend A, De Keyser J. Continuous pulse oximetry in acute hemiparetic stroke. J Neurol Sci. 2000;179(1):65-9.

27. Roffe C, Sills S, Halim M, Wilde K, Allen MB, Jones PW, et al. Unexpected nocturnal hypoxia in patients with acute stroke. Stroke. 2003;34(11):2641-5.

28. Ali K, Cheek E, Sills S, Crome P, Roffe C. Day-night differences in oxygen saturation and the frequency of desaturations in the first 24 hours in patients with acute stroke. J Stroke Cerebrovasc Dis. 2007;16(6):239-44.

29. Roffe C, Frohnhofen H, Sills S, Hodsoll J, Allen MB, Jones PW. Frequency of nocturnal hypoxia in clinically stable patients during stroke rehabilitation. Clin Rehabil. 2010:24(3):267-75.

30. Hand P, Wardlaw JM, Rowat AM, Haisma J, Lindley R, Dennis MS. Magnetic resonance brain imaging in patients with acute stroke: feasibility and patient related difficulties. J Neurol Neurosurg Psychiatr. 2005;76(11):1525-7.

31. Rowat AM, Wardlaw JM, Dennis MS, Warlow CP. Patient positioning influences oxygen saturation in the acute phase of stroke. Cerebrovasc Dis. 2001;12(1):66-72

32. Tyson SF, Nightingale P. The effects of position on oxygen saturation in acute stroke: a systematic review. Clin Rehabil. 2004;18(8):863-71.

33. Dutta D, Bannerjee M, Chambers T. Is tube feeding associated with altered arterial oxygen saturation in stroke patients? Age Ageing. 2004;33(5):493-6

34. Dutta D, Wood T, Thomas R, UI Haq MA. Is overnight tube feeding associated with hypoxia in stroke? Age Ageing. 2006;35(6):627-9.
35. Rowat AM, Wardlaw JM, Dennis MS, Warlow CP. Does feeding alter arterial oxygen saturation in patients with acute stroke? Stroke. 2000;31(9):2134-40

36. Moroney J, Bagiella E, Desmond D, Paik M, Stern Y, Tatemichi T. Cerebral hypoxia and ischemia in the pathogenesis of dementia after stroke. Ann NY Acad Sci. 1997;826(1):433-6.

37. Rowat AM, Dennis MS, Wardlaw JM. Hypoxaemia in acute stroke is frequent and worsens outcome. Cerebrovasc Dis. 2006;21(3):166-72.

38. Celik C, Can AG, Yalbuzdag SA, Ozer M. Nocturnal hypoxia and functional outcome in stroke patients1. NeuroRehabilitation. 2015;36(3):339-43.

39. Patel SK, Hanly PJ, Smith EE, Chan W, Coutts SB. Nocturnal hypoxemia is associated with white matter hyperintensities in patients with a minor stroke or transient ischemic attack. J Clin Sleep Med. 2015;11(12):1417-24.

40. Smith CJ, Kishore AK, Vail A, Chamorro A, Garau J, Hopkins SJ, et al. Diagnosis of stroke-associated pneumonia: recommendations from the pneumonia in stroke consensus group. Stroke. 2015;46(8):2335-40.

41. Kishore AK, Vail A, Chamorro A, Garau J, Hopkins SJ, Di Napoli M, et al. How is pneumonia diagnosed in clinical stroke research? A systematic review and meta-analysis. Stroke. 2015:46(5):1202-9.

42. Papavasileiou V, Milionis H, Smith CJ, Makaritsis K, Bray BD, Michel P, et al. External validation of the prestroke independence, sex, age, national institutes of health stroke scale (isan) score for predicting stroke-associated pneumonia in the athens stroke registry. J Stroke Cerebrovasc Dis. 2015;24(11):2619-24

43. Emsley HC, Hopkins SJ. Acute ischaemic stroke and infection: recent and emerging concepts. Lancet Neurol. 2008;7(4):341-53.

44. Kalra L, Irshad S, Hodsoll J, Simpson M, Gulliford M, Smithard D, et al. Prophylactic antibiotics after acute stroke for reducing pneumonia in patients with dysphagia (STROKE-INF): a prospective, cluster-randomised, open-label, masked endpoint, controlled clinical trial. Lancet. 2015;386(10006):1835-44.

45. Westendorp WF, Vermeij JD, Zock E, Hooijenga IJ, Kruyt ND, Bosboom $\mathrm{HJ}$, et al. The preventive antibiotics in stroke study (PASS): a pragmatic randomised open-label masked endpoint clinical trial. Lancet. 2015:385(9977):1519-26.

46. Smith CJ, Bray BD, Hoffman A, Meisel A, Heuschmann PU, Wolfe CD, et al. Can a novel clinical risk score improve pneumonia prediction in acute stroke care? A UK multicenter cohort study. J Am Heart Assoc 2015:4(1):e001307.

47. Chumbler NR, Williams LS, Wells CK, Lo AC, Nadeau S, Peixoto AJ, et al. Derivation and validation of a clinical system for predicting pneumonia in acute stroke. Neuroepidemiology. 2010;34(4):193-9.

48. LiY, Song B, Fang H, Gao Y, Zhao L, XuY. External validation of the A2DS2 score to predict stroke-associated pneumonia in a Chinese population: a prospective cohort study. PLoS ONE. 2014:9(10):e109665.

49. Bath PM, Scutt P, Love J, Clave P, Cohen D, Dziewas R, et al. Pharyngea electrical stimulation for treatment of dysphagia in subacute stroke: a randomized controlled trial. Stroke. 2016:47(6):1562-70.

50. Martino R, Foley N, Bhogal S, Diamant N, Speechley M, Teasell R. Dysphagia after stroke: incidence, diagnosis, and pulmonary complications. Stroke. 2005;36(12):2756-63.

51. Cohen DL, Roffe C, Beavan J, Blackett B, Fairfield CA, Hamdy S, et al. Poststroke dysphagia: a review and design considerations for future trials. Int $J$ Stroke. 2016:11(4):399-411.

52. Shay K. Infectious complications of dental and periodontal diseases in the elderly population. Clin Infect Dis. 2002:34(9):1215-23.

53. Dai R, Lam OL, Lo EC, Li LS, Wen Y, McGrath C. A systematic review and meta-analysis of clinical, microbiological, and behavioural aspects of oral health among patients with stroke. J Dent. 2015:43(2):171-80.

54. Yaggi HK, Concato J, Kernan WN, Lichtman JH, Brass LM, Mohsenin V. Obstructive sleep apnea as a risk factor for stroke and death. N Engl J Med. 2005;353(19):2034-41

55. Broadley SA, Jørgensen L, Cheek A, Salonikis S, Taylor J, Thompson PD, et al. Early investigation and treatment of obstructive sleep apnoea after acute stroke. J Clin Neurosci. 2007:14(4):328-33.

56. Martínez-García MÁ, Soler-Cataluña JJ, Ejarque-Martínez L, Soriano Y, Román-Sánchez $\mathrm{P}$, Illa FB, et al. Continuous positive airway pressure treatment reduces mortality in patients with ischemic stroke and obstructive sleep apnea: a 5-year follow-up study. Am J Respir Crit Care Med. 2009:180(1):36-41. 
57. Yaggi H, Mohsenin V. Obstructive sleep apnoea and stroke. Lancet Neurol. 2004;3(6):333-42.

58. Alapat PM. Obstructive sleep apnea and stroke. Curr Res Med Rev. 2007;3(4):241-4.

59. Gami AS, Pressman G, Caples SM, Kanagala R, Gard JJ, Davison DE, et al. Association of atrial fibrillation and obstructive sleep apnea. Circulation. 2004;110(4):364-7.

60. Munoz R, Duran-Cantolla J, Martínez-Vila E, Gallego J, Rubio R, Aizpuru F, et al. Severe sleep apnea and risk of ischemic stroke in the elderly. Stroke. 2006;37(9):2317-21.

61. Arzt M, Young T, Finn L, Skatrud JB, Bradley TD. Association of sleep-disordered breathing and the occurrence of stroke. Am J Respir Crit Care Med. 2005;172(11):1447-51.

62. Ezeugwu VE, Olaogun M, Mbada CE, Adedoyin R. Comparative lung function performance of stroke survivors and age-matched and sex-matched controls. Physiother Res Int. 2013;18(4):212-9.

63. Teixeira-Salmela LF, Parreira VF, Britto RR, Brant TC, Inacio EP, Alcantara TO, et al. Respiratory pressures and thoracoabdominal motion in community-dwelling chronic stroke survivors. Arch Phys Med Rehabil. 2005:86(10):1974-8.

64. Voyvoda N, Yucel C, Karatas G, Oguzulgen I, Oktar S. An evaluation of diaphragmatic movements in hemiplegic patients. Br J Radiol. 1012;2012(85):411-4.

65. Gomes-Neto M, Saquetto MB, Silva CM, Carvalho VO, Ribeiro N, Conceicao CS. Effects of respiratory muscle training on respiratory function, respiratory muscle strength, and exercise tolerance in patients poststroke: a systematic review with meta-analysis. Arch Phys Med Rehabil. 2016;97:1994-2001

66. Pongmoragot J, Rabinstein AA, Nilanont Y, Swartz RH, Zhou L, Saposnik G. Pulmonary embolism in ischemic stroke: clinical presentation, risk factors, and outcome. J Am Heart Assoc. 2013;2(6):e000372.

67. Amin AN, Lin J, Thompson S, Wiederkehr D. Rate of deep-vein thrombosis and pulmonary embolism during the care continuum in patients with acute ischemic stroke in the United States. BMC Neurol. 2013;13:17.

68. Tanislav C, Puille M, Pabst W, Reichenberger F, Grebe M, Nedelmann M, et al. High frequency of silent pulmonary embolism in patients with cryptogenic stroke and patent foramen ovale. Stroke. 2011;42(3):822-4.

69. Tan CK, Lai CC. Neurogenic pulmonary edema. CMAJ. 2007;177(3):249-50.

70. Antoncic I, Dunatov S, Sosic M, Antulov R, Bralic M. Neurogenic pulmonary edema caused by bilateral medial medullary infarction. Neurol Sci. 2015;36(4):645-6.

71. Medford MA, Piantadosi CA. Oxygen toxicity: from cough to convulsion. Studies on experimental toxicology and pharmacology. Switzerland: Springer; 2015. p. 427-47.
72. Lumb AB, Walton LJ. Perioperative oxygen toxicity. Anesthesiol Clin. 2012;30(4):591-605.

73. Thomson L, Paton J. Oxygen toxicity. Paediatr Respir Rev. 2014;15(2):120-3.

74. Van Ooij P, Hollmann M, van Hulst R, Sterk P. Assessment of pulmonary oxygen toxicity: relevance to professional diving; a review. Respir Physiol Neurobiol. 2013;189(1):117-28.

75. Party ISW. National clinical guideline for stroke. London: Royal College of Physicians; 2012.

76. Committee ESOE, Committee EW. Guidelines for management of ischaemic stroke and transient ischaemic attack 2008. Cerebrovasc Dis. 2008;25(5):457-507.

77. Jauch EC, Saver JL, Adams HP, Bruno A, Demaerschalk BM, Khatri P, et al. Guidelines for the early management of patients with acute ischemic stroke a guideline for healthcare professionals from the American Heart Association/American Stroke Association. Stroke. 2013;44(3):870-947.

78. Callaway CW, Donnino MW, Fink EL, Geocadin RG, Golan E, Kern KB, et al. Part 8: post-cardiac arrest care 2015 American Heart Association Guidelines update for cardiopulmonary resuscitation and emergency cardiovascular care. Circulation. 2015;132(18 suppl 2):S465-82.

79. Ronning OM, Guldvog B. Should stroke victims routinely receive supplemental oxygen? A quasi-randomized controlled trial. Stroke. 1999;30(10):2033-7.

80. Singhal AB, Benner T, Roccatagliata L, Koroshetz WJ, Schaefer PW, Lo $\mathrm{EH}$, et al. A pilot study of normobaric oxygen therapy in acute ischemic stroke. Stroke. 2005;36(4):797-802.

81. Padma MV, Bhasin A, Bhatia R, Garg A, Singh MB, Tripathi M, et al. Normobaric oxygen therapy in acute ischemic stroke: a pilot study in Indian patients. Ann Indian Acad Neurol. 2010;13(4):284-8.

82. Roffe C, Ali K, Warusevitane A, Sills S, Pountain S, Allen M, et al. The SOS pilot study: a RCT of routine oxygen supplementation early after acute stroke-effect on recovery of neurological function at one week. PLoS ONE. 2011;6(5):e19113.

83. Ali K, Warusevitane A, Lally F, Sim J, Sills S, Pountain S, et al. The stroke oxygen pilot study: a randomized controlled trial of the effects of routine oxygen supplementation early after acute stroke-effect on key outcomes at six months. PLoS ONE. 2014;8(6):e59274.

84. Roffe C, Nevatte T, Crome P, Gray R, Sim J, Pountain S, et al. The Stroke Oxygen Study (SO2S) - a multi-center, study to assess whether routine oxygen treatment in the first 72 hours after a stroke improves longterm outcome: study protocol for a randomized controlled trial. Trials. 2014;15:99.

\section{Submit your next manuscript to BioMed Central and we will help you at every step:}

- We accept pre-submission inquiries

- Our selector tool helps you to find the most relevant journal

- We provide round the clock customer support

- Convenient online submission

- Thorough peer review

- Inclusion in PubMed and all major indexing services

- Maximum visibility for your research

Submit your manuscript at www.biomedcentral.com/submit
() Biomed Central 